\title{
COD Reduction of Anaerobically Digested Distillery Spentwash By Electro-Fenton Process
}

\author{
V. P. Patil ${ }^{1}$, M. B. Tantak ${ }^{2}$, D.S. Nimbalkar ${ }^{3}$, S. S. Patil ${ }^{4}$ \\ Department of Environmental Sciences, \\ Dr. Babasaheb Ambedkar Marathwada University, Aurangabad, India ${ }^{1,4}$ \\ Post graduate student at Department of Environmental Sciences ${ }^{2}$ \\ Vasantdada Sugar Institute, Pune, India ${ }^{3}$ \\ Email:vivekppatil12@gmail.com ${ }^{1}$, sushshrey1@gmail.com ${ }^{4}$
}

\begin{abstract}
Advanced oxidation processes (AOPs) are powerful for degrading most organic and inorganic compounds, which led the way in the treatment of wastewater and so has attracted great attention. In present study shows, COD reduction efficiency of anaerobically digested distillery effluent by Electro-Fenton (EF) process, as it is one of the AOPs, evaluated in lab scale experiments. An electrochemical batch reactor furnished with two iron electrodes, connected parallel to each other and used to carried out the experiment. The E-Fenton process was studied for optimization of power consumption, agitation speed and the reaction time under different $\mathrm{pH}$ conditions (3.0, 5.0 and 7.0). In this process COD reduction up to $24.9 \%$ was achieved at $18 \mathrm{~W}$ power consumption in acidic $\mathrm{pH} 3$ with $500 \mathrm{rpm}$ agitation speed and within 120 min reaction time. Electro-Fenton process can successfully apply for the treatment of ADSW having high organic content in the first stage only, because organic pollutants does not degrade completely and further treatment is necessary before discharging it into natural ecosystem.
\end{abstract}

Key words- Anaerobically digested distillery spentwash, AOP, Electro-Fenton process, COD reduction

\section{INTRODUCTION}

Distillery industry is one of the heavily polluting industry out of seventeen prescribed by Ministry of Environment, Forest and Climate Change (MoEFCC) Govt. Of India which is covered under central action plan [1]. The wastewater produced from distillation of fermented slop is very complex, caramelized and bulky agro industrial waste which is having temperature ranges between 70-80 ${ }^{\circ} \mathrm{C}$, dark brown in color, acidic in nature (low $\mathrm{pH}$ ), with high concentration of organic materials and solids. Pollution load of the distillery effluent depends on the purity of molasses, unit operation for handling of molasses and recovery of alcohols [2]. Most Indian distilleries exclusively use cane molasses as raw material for fermentation [3]. The residue of the fermented mash, which comes out as liquid waste, is termed as spent wash [4]. On an average 8-15 $\mathrm{L}$ of effluent is generated for every liter of alcohol produced [5]. Its complex nature is due to existence of the brown polymers, melanoidins, which formed by Maillard amino carbonyl reaction. These composites have antioxidant properties, which render to many toxic microorganisms especially those typically present in wastewater treatment processes [6]. In addition with melanoidins, the other recalcitrant complexes present in the distillery effluent are caramel, variety of sugar decomposition products, anthocyanins, tannins and dissimilar xenobiotic compounds [2]. Various treatment technologies have been explored for reducing the pollution load of distillery effluent i.e spentwash. Biological treatment used for distillery spent wash is either aerobic or anaerobic, but most of the distilleries in India use anaerobic treatment as pretreatment to the distillery spentwash. Anaerobic process is a very promising re-emerging technology which has stimulating advantages as compared to aerobic treatment. It has high capacity of degrading concentrated and robust substances. It produces small amount of sludge, needs less energy and can become profitable by cogeneration of valuable biogas [7]. The anaerobically digested distillery spentwash is necessary to cope up with environmental standards.

Table 1. Characteristics of anaerobically treated distillery effluent [8].

\begin{tabular}{|l|l|}
\hline \multicolumn{1}{|c|}{ Parameters } & \multicolumn{1}{c|}{ Values } \\
\hline pH & $7.5-8$ \\
\hline BOD5 (mg L-1) & $8000-10,000$ \\
\hline COD (mg L-1) & $45,000-52,000$ \\
\hline Total solid (TS) (mg L-1) & $70,000-75,000$ \\
\hline $\begin{array}{l}\text { Total volatile solid (TVS) } \\
\text { (mg L-1) }\end{array}$ & $68,000-70,000$ \\
\hline $\begin{array}{l}\text { Total suspended solid (TSS) } \\
\text { (mg L-1) }\end{array}$ & $38,000-42,000$ \\
\hline $\begin{array}{l}\text { Total dissolved solids (TDS) } \\
\text { (mg L-1) }\end{array}$ & $30,000-32,000$ \\
\hline Chlorides (mg L-1) & $7000-9000$ \\
\hline Phenols (mg L-1) & $7000-8000$ \\
\hline Sulphate (mg L-1) & $15000-5000$ \\
\hline Phosphate (mg L-1) & $4000-4200$ \\
\hline Total nitrogen (mg L-1)
\end{tabular}

These values are much higher than the permissible limits and effluent standards notified for molasses-based distilleries deserving maximum BOD level of $30 \mathrm{mg} / \mathrm{lit}$ for disposal to surface water and $100 \mathrm{mg} / \mathrm{lit}$ for disposal on land [9].

\subsection{Advance Oxidation Process (AOP)}

The main tool of AOPs function is the generation of highly reactive free radicals. Hydroxyl radicals $(\mathrm{OH} \bullet)$ are operative in destroying organic chemicals because they are reactive electrophiles (electron preferring) they react rapidly and non-selectively with almost all electron-rich organic compounds. AOPs are centered on the chemistry of hydroxyl radicals $(\mathrm{OH} \bullet, \mathrm{E}=2.8 \mathrm{~V}$ versus $\mathrm{SHE})$. They have powerful technologies to treat wastewater containing recalcitrant organic compounds [10]. Hydroxyl radical reacts with pollutants in a non-selective 
way, the pollutant oxidized into mineral products, yielding $\mathrm{CO} 2$ and inorganic ions [11].

\subsubsection{Electro-Fenton process}

In presence of ferrous ions and in acidic aqueous medium the oxidation power will be enhanced due to the production of a very reactive one-electron oxidizing agent hydroxyl radical $(\bullet \mathrm{OH})$ from the Fenton reaction.

Compared to the conventional Fenton process, the electro-Fenton process has the benefit of allowing better control of the process and ducking the storing and transport of the $\mathrm{H}_{2} \mathrm{O}_{2}$. The kinetics of the electrochemical method are about 100-fold faster than biological oxidation methods [12]. Electrochemical techniques are beneficial as environmental compatibility, versatility, energy efficiency, safety, selectivity, amenability to automation, and cost-effectiveness [13]. This electroFenton process can produce $\cdot \mathrm{OH}$ radicals by the simultaneous electrochemical reduction of $\mathrm{O}_{2}$ in the presence of catalytic amounts of ferrous ions [14].

The-most important factor for the E-Fenton process is $\mathrm{pH}$. Generally, Fenton processes are conducted in acidic medium. Most of the studies reported that the optimum $\mathrm{pH}$ of Fenton process is around $3.00[15,16]$. Acidic medium is the auspicious condition for the production of $\mathrm{H}_{2} \mathrm{O}_{2}$ [17]. Due to the revival of $\mathrm{Fe}^{2+}$, through reaction between $\mathrm{Fe}^{3+}$ and $\mathrm{H}_{2} \mathrm{O}_{2}$, Fenton process becomes less effective at $\mathrm{pH}<3$ [18]. At upper $\mathrm{pH}$, the efficiency of $\mathrm{E}$ Fenton process declines rapidly, especially $\mathrm{pH}>5$. This happens because $\mathrm{H}_{2} \mathrm{O}_{2}$ is unstable in basic solution. $\mathrm{H}_{2} \mathrm{O}_{2}$ rapidly decomposes oxygen and water at neutral to high $\mathrm{pH}$ [19].

Efficiency of Electro-Fenton treatment assessed in laboratory scale experiment, which is one of the electrochemical treatment applications. The process includes the combined advantages of electrochemical and Fenton treatment methods.

\section{MATERIAL AND METHODS}

\subsection{Material}

Anaerobically Digested Spent Wash (ADSW) collected from M/s. Someshwar Sahakari Sakhar Karkhana Ltd (distillery unit) located in Maharashtra state of India. It was collected from outlet of Continuous stirred tank reactors (CSTR). The major physico-chemical characteristics of the ADSW at the time of collection were: $\mathrm{pH}$ : 7.3, COD: 24,800 mg/L, BOD: 6,200 mg/L, conductivity: $11 \mathrm{mS} 20 / \mathrm{cm}$, color: dark-brown, odor: burnt sugar.

\subsection{Methods}

Laboratory scale experiment were performed in batch mode at room temperature and 0.5-liter capacity glass beaker arranged with iron electrode as cathode and an anode both at the distance of $4 \mathrm{~cm}$ from each other. The dimensions of electrode were $\$ 2 \mathrm{~mm} \times 4 \mathrm{~cm}$. The electrodes were situated vertically and fix at $4 \mathrm{~cm}$ away from each other. Both electrode were deepen in reactor with 0.3-liter working volume. The electrode was linked to a DC power supply provide power at $3,9,12,15,18$ $\mathrm{W}$ electric current intensities measured throughout the experiment. The batch was stirred (100-500 rpm) with a magnetic bar (REMI make 2MLH magnetic stirrer) to ensure homogeneity and transport of reactants toward/away from the electrodes. The effect of $\mathrm{pH}$ on electrochemical oxidation was studied at different $\mathrm{pH}$ (3.00, 5.00, 7.00). The $\mathrm{pH}$ of the reaction mixture was measured using a pH meter (EQUIPTRONICS, EQ. 661, India) and adjusted appropriately for every experiment using $0.1 \mathrm{M} \mathrm{H}_{2} \mathrm{SO}_{4}$.

\subsubsection{Electro-Fenton process}

The electro-Fenton process was carried out with iron

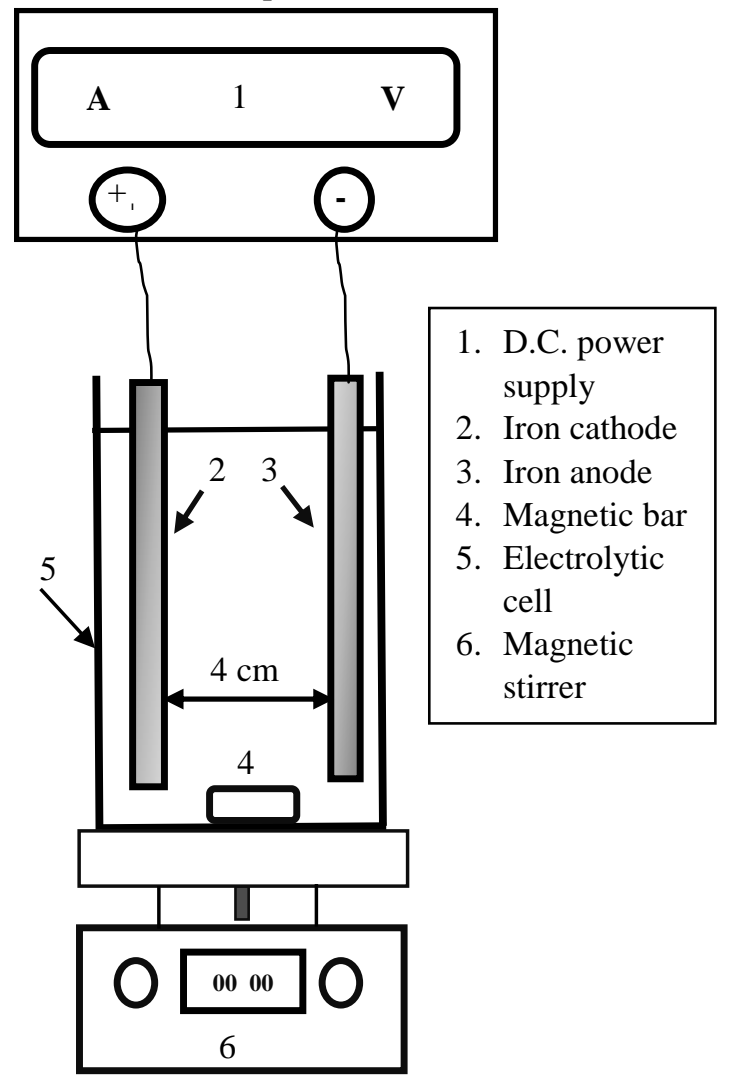

Figure 1: Electro-Fenton Experimental Setup

U. Kurt et. al, 2007 [20]

based electrode cathode and anode, the $\mathrm{H}_{2} \mathrm{O}_{2}$ is produced electrochemically via oxygen reduction; then addition of $\mathrm{Fe}^{2+}$ into the system generates analogously $\mathrm{OH} \cdot$ radicals in the classical Fenton's reaction between $\mathrm{Fe}^{2+}$ and $\mathrm{H}_{2} \mathrm{O}_{2}$ [21]. Ferrous ions acts as coagulation materials in the electro-chemical treatment. On the other hand, ferrous ions create hydroxyl radicals and catalyze the Fenton reaction.

\subsubsection{Analytical Procedures}

Chemicals were obtained from Merck, India which has analytical reagent (AR) grade. The $\mathrm{pH}$ of the reaction mixture was measured by using a $\mathrm{pH}$ meter (EQUIPTRONICS, EQ.661, India) and adjusted appropriately for every experiment using $0.1 \mathrm{M} \mathrm{H} 2 \mathrm{SO} 4$. COD removal of ADSW after each treatment was check, by close reflux method (colorometric method) in accordance with standard methods of water and wastewater analysis standard methods in APHA AWWA. 


\section{EXPERIMENTAL RESULT AND DISCUSSION}

In this experiment, COD removal by E-Fenton process were studied with various impact causing parameters and results are discussed below in details.

\subsection{Effect of $p H$}

Figure 2: Effect of $\mathrm{pH}$ on COD removal

$\mathrm{EF}$ processes were perform for three different $\mathrm{pH}$ i.e.

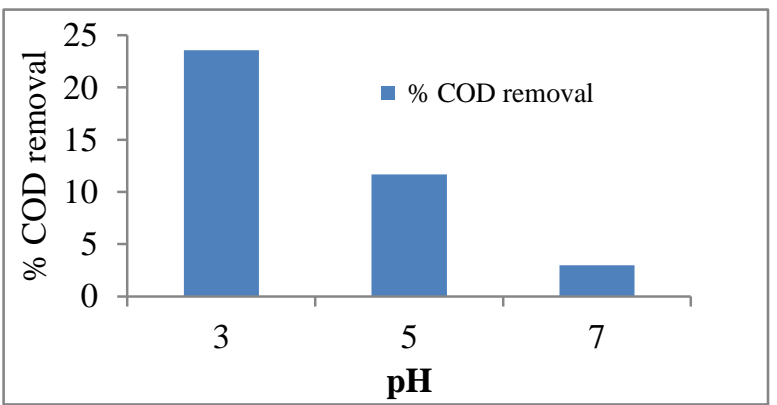

$3.00,5.00$ and 7.00, and other parameter were fixed at each $\mathrm{pH}$ variation experiment. The agitation speed was set at $500 \mathrm{rpm}$ for $120 \mathrm{~min}$ at $15 \mathrm{~W}$ current intensity. Fig. 2. shows that Removal of COD by E-Fenton process are more efficient in acidic medium than in neutral medium. In E-Fenton process maximum $23.55 \% \mathrm{COD}$ observed at $3.00 \mathrm{pH}$. With increase in $\mathrm{pH}$ to neutral, the COD removal efficiency decreases. COD removal efficiency reduces up to $11.39 \%$ by increase in $\mathrm{pH}$ to 5.00 and at neutral $\mathrm{pH}$ (7.00) COD removal efficiency observed up to $2.98 \%$. Most of the literature also reported optimum $\mathrm{pH}$ of E-Fenton process is 3.00.

\subsection{Effect of treatment time}

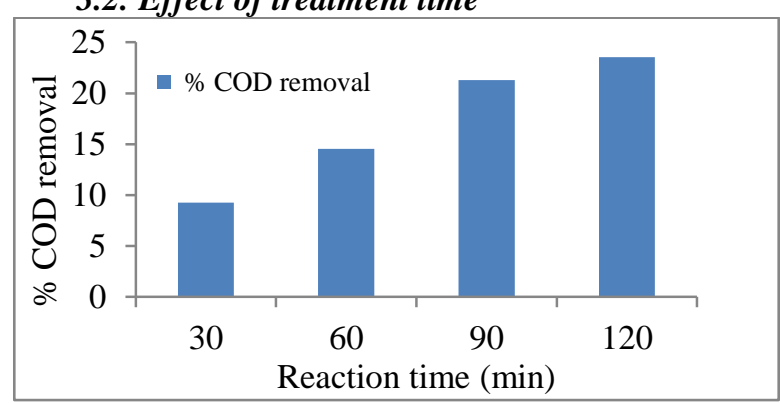

Figure 3: Effect of treatment time on COD removal

The effect of treatment time of E-Fenton process shown in fig. 3. E-Fenton experiment conducted at optimized $\mathrm{pH}$ $3.00,15 \mathrm{~W}$ power supply with agitation speed of 500 rpm. To study the effect of treatment time process were conduct for $30,60,90$ and 120 min interval in batch rector. COD removal efficiency $9.27 \%, 14.52 \%, 21.31 \%$ and $23.55 \%$ achieved at $30,60,90$ and $120 \mathrm{~min}$ time respectively. COD removal efficiency gradually increase with increase in time and conquered constant after 120 min. COD reduction was observed till complete consumption of the Fenton's reagent that has been added to the system.

\subsection{Effect of agitation speed}

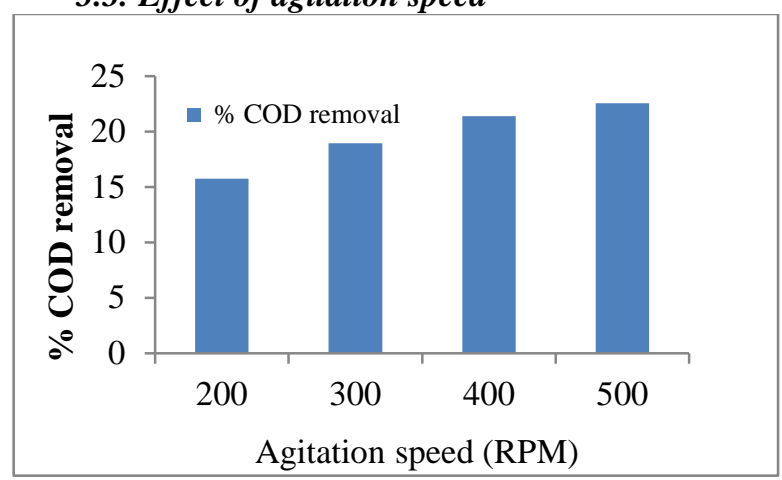

Figure 4: Effect of agitation speed on COD removal E-Fenton process conducted at various agitation speed i.e. $200,300,400$, and $500 \mathrm{rpm}$ to evaluate the effect of

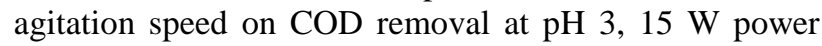
and 120 min treatment time. There was a

Steady increase in COD reduction efficiency from $15.73 \%$ to $22.55 \%$ with an increase in agitation speed from 200 to $500 \mathrm{rpm}$. This is because, with an increase in agitation speed, the increase in movement of ADSW, which reacts more rapidly with electrodes and generate more ions. Increasing the agitation speed beyond 400-500 rpm doesn't shows major effect on the COD removal efficiency. At higher agitation speeds, the Fenton's reagent gets well mixed which results in increased oxidation of the organic pollutants [22].

\subsection{Effect of current intensity}

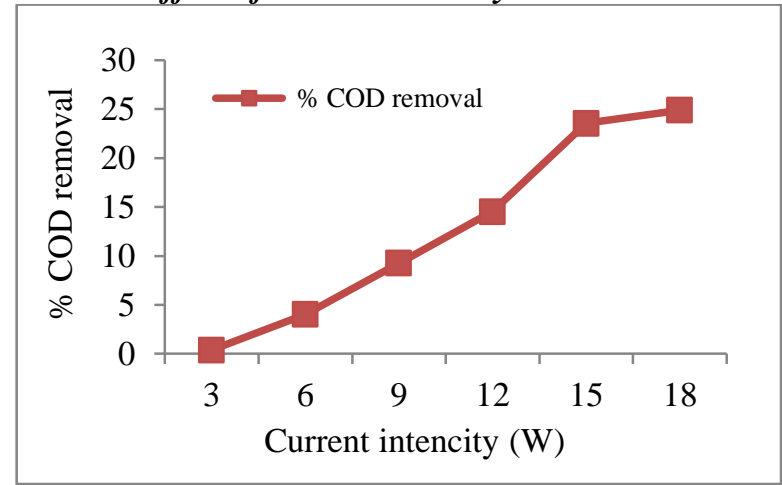

Figure 5: Effect of current intensity on COD removal Current intensity is a significant parameter that exerts a large impact on the degradation rate of recalcitrant pollutants, which undergoes Fenton electrolysis. The electro-Fenton process based on the continuous electrogeneration of $\mathrm{Fe}^{2+}$ ion. To study its effect, a sequence of electrolysis reaction were investigated with varying applied current intensity from $3-18 \mathrm{~W}$ to $300 \mathrm{ml}$ ADSW at $\mathrm{pH}$ of 3.00 for $120 \mathrm{~min}$ with $500 \mathrm{rpm}$. Cumulative current intensity led to the rise in COD reduction efficiency. Higher current intensity increases the amount of $\mathrm{H}_{2} \mathrm{O}_{2}$ produced, thus increasing the number of $\bullet \mathrm{OH}$ in the electrolyte, which are highly reactive and responsible for the degradation of recalcitrant pollutants. In addition, higher regeneration of ferrous ion from ferric ion with higher voltage increases the efficiency of reactions [23]. The rate of dissociation of iron electrode increased with an increase in current intensity. Initially at $3 \mathrm{~W}$ COD reduction efficiency was $0.4 \%$ that increased by $1.3 \%$, $9.27 \%, 14.52 \%, 23.55 \%$ and $24.9 \%$ at $6,9,12,15$, and $18 \mathrm{~W}$ current intensity respectively, achieved in $120 \mathrm{~min}$ 
of electrolysis time. After $15 \mathrm{~W}$ rate of COD, reduction efficiency goes down. However, the rate of COD reduction toughly depends on the current intensity and concentration of the organic matter present in ADSW.

\section{CONCLUSION}

In this study, the efficiency of COD reduction in ADSW was evaluate for different variables such as current intensity, $\mathrm{pH}$, reaction time and solution agitation speed, which give rise to significant differences in the efficiency of the electro-Fenton process. For Electro-Fenton process, 24.9\% ADSW COD reduction was attained using Fe-Fe electrode in electrolysis treatment. The COD removal efficiency found more at low $\mathrm{pH}$ (3.00), agitation speed $500 \mathrm{rpm}$, treatment time $120 \mathrm{~min}$ and power consumption $15 \mathrm{~W}$ and $18 \mathrm{~W}$.

\section{Acknowledgments}

Sincere thanks are extended to the Director General, Vasantdada Sugar Institute, Pune for support and permission to do research work in the institute.

\section{REFERENCES}

[1] CPCB (2012) News letter from ENVIS center

[2] R.A. Pandey, A. Malhotra, S. Tankhiwale, S. Pande, P.P. Pathe, S.N. Kaul, (2003) Treatment of biologically treated distillery effluent—a case study, Int. J. Environ. Study 60, 263-275

[3] B.K. Handa, R. Seth, (1990) Waste management in distillery industry, J. IAEM 17, 44-54

[4] G.R. Pathade, A review of current technologies for distillery wastewater treatment, in: P.K. Goel (Ed.), (2003) Advances in Industrial Wastewater Treatment, ABD Publishers, Jaipur, India, pp. 180239.

[5] N.K. Saha, M. Balakrishnan, V.S. Batra, (2005) Improving industrial water use: case study for an Indian distillery, Res. Conserv. Recycl 43, 163-174.

[6] V. Kumar, L. Wati, F. FitzGibbon, P. Nigan, I.M. Banat, D. Singh, R. Marchant, (1997) Bioremediation and decolorization of anaerobically digested distillery spent wash, Biotech. Lett 19, 311313

[7] L. Mailleret, O. Bernard, J.P. Steyer, (2003) Robust regulation of anaerobic digestion process, Water Sci. Technol. 48, 87-94.

[8] B.K. Acharya, S. Mohana, D. Madamwar, (2008) Anaerobic treatment of distillery spent wash: A study on upflow anaerobic fixed film bioreactor, Biores. Technol. 99, 4621-4626.

[9] The Environment (Protection) Rules, 1986 SheduleVI

[10]E. Brillas, C. Arias, P.L. Cabot, F. Centellas, J.A. Garrido, R.M. Rodríguez, (2006) Degradation of organic contaminants by electrochemical oxidation methods, Port. Electrochem. Acta 24, 159-189.

[11]E.S. Elmolla, M. Chaudhuri, (2010) Comparison of different advanced oxidation processes for treatment of antibiotic aqueous solution, Desalination 256, 4347

[12]L. Szpyrkowicz, S.N. Kaul, R.N. Neti, (2005) Tannery wastewater treatment by electro-oxidation coupled with a biological process, J. Appl. Electrochem. 35, 381-390

[13] Rajeshwar, K., Ibanez, J. \& Swain, G. M. (1994) Electrochemistry and the environment. J. Appl. Electrochem. 24, 1077-1091.

[14] A. Wang, J. Qu, J. Ru, H. Liu, J. Ge, (2005) Mineralization of an azo dye Acid Red 14 by electro- Fenton's reagent using an activated carbon fiber cathodell, Dyes and Pig. 65, 227- 233,.

[15]M.M. Ghoneim, H.S. El-Desoky, N.M. Zidan, (2011) Electro-Fenton oxidation of Sunset Yellow FCF azo-dye in aqueous solutions, Desalination 274, 22-30.

[16] M. Zhou, Q. Yu, L. Lei, G. Barton, (2007) ElectroFenton method for the removal of methyl red in an efficient electrochemical system, Sep. Purif. Technol. 573, 380-387.

[17]C.T. Wang, W.L. Chou, M.H. Chung, Y.M. Kuo, (2010) COD removal from real dyeing wastewater by electro-Fenton technology using an activated carbon fiber cathode, Desalination 253, 129-134.

[18] J.H. Ramirez, F.M. Duarte, F.G. Martins, C.A. Costa, L.M. Madeira, (2008) Modelling of the synthetic dye Orange II degradation using Fenton's reagent: from batch to continuous reactor operation, Chem. Eng. J. 148, 394-404.

[19]H. Shemer, K.G. Linden, (2006) Degradation and by-product formation of diazinon in water during $\mathrm{UV}$ and UV/H2O2 treatment, J. Hazard. Mater. 136, 553-559.

[20] U. Kurt, Omer Apaydin, M. Talha Gonullu, (2007) Reduction of COD in wastewater from an organized tannery industrial region by Electro-Fenton process, Hazardous Materials 143, 33-40

[21]Brillas, E., Calpe, J.C., Casado, J., (2000) Mineralization of 2,4-D by advanced electrochemical oxidation processes. Water Research, 34 (8): 2253-2262.

[22] CharlesDavid, M.Arivazhagan, Decolorization of distillery spentwash effluent by electro-oxidation (EC and EF) and Fenton processes: A comparative study, Ecotoxicol. Environ. Saf. 121, 142-148.

[23] Estrada., A. L., Li, Y. Y., Wang, A., (2012) Biodegradability enhancement of wastewater containing cephalexin by means of the electroFenton oxidation process. J.Hazard. Mater. 227$228,41-48$. 